\title{
Comparison of Coliform Contamination and Endotoxin Levels in Raw
}

\section{Cow's Milk}

\author{
Fatemeh Afshari Asfidoajani ${ }^{1}$ and Maryam Mohammadi Sichani ${ }^{1,{ }^{*}}$ \\ ${ }^{1}$ Department of Microbiology, Falavarjan Branch, Islamic Azad University, Isfahan, Iran \\ "Corresponding author: Department of Microbiology, Falavarjan Branch, Islamic Azad University, Isfahan, Iran. Tel: +98-9133092823, Email: mohamadi_m@iaufala.ac.ir
}

Received 2017 August 02; Revised 2018 January 23; Accepted 2018 February 04.

\begin{abstract}
Background: Milk forms a considerable part of the necessary materials needed for the physical and mental growth of all community members, especially children and the elderly. Since milk is a suitable culture medium for the growth of many bacteria, strict standards have been introduced for its safety. The aim of this study was to evaluate the coliform contamination of raw cow's milk and the level of endotoxin in it.

Methods: Using random sampling, 43 samples of raw cow's milk were collected in Isfahan, Iran. Coliforms were identified by biochemical tests. Then, the molecular method was employed for the definitive identification of the coliforms. Moreover, endotoxin levels were assessed employing the limulus amebocyte lysate (LAL) test.

Results: Results indicated the presence of coliforms in 17 (39.45\%) of the raw milk samples. Based on the molecular identification of the isolated coliforms, 10 samples were contaminated with Escherichia coli, five with Enterobacter spp., and two with Klebsiella pneumoniae. The results of the LAL test showed that 17 samples contained 0.250 units, six samples contained 0.125 units, and 20 samples contained 0.063 units of endotoxin.

Conclusions: There was a significant correlation between coliform contamination of raw cow's milk and 0.250 unit/mL endotoxin $(\mathrm{P}<0.001)$. Increasing the number of coliforms in milk samples is consistent with the increase in endotoxin levels.
\end{abstract}

Keywords: Milk, Coliform Bacilli, Endotoxin, Limulus Amebocyte Lysate Test

\section{Background}

Milk is a food capable of satisfying most human nutritional needs. It is considered one of the most important animal proteins. It contains various valuable vitamins and minerals, the most important of which is calcium. Absorption of milk calcium improves considerably in the presence of lactose $(1,2)$.

Milk is free of bacteria or contains very few of them if it is milked from healthy dairy cows. The sanitary quality of milk, which must be considered by livestock keepers, is assessed based on total bacterial count and somatic cell count (3). Bacteria present in milk may acidify it, give it a bad taste, cause gelation of milk, and transmit diseases (4). Therefore, bacterial count of milk can be one of the important criteria in predicting the health of cows and the sanitary conditions of milking due to the fact that it indicates the manner of transportation and storage of raw milk in addition to serving as a common method of and being the most significant criterion for the process of assessing raw milk quality (5).

The presence of coliforms in milk indicates secondary infections and is a sign of it being unsafe for human consumption. Coliforms bacteria are destroyed very rapidly during the pasteurization process. Based on current standards, the number of coliforms must be less than 100 $\mathrm{CFU} / \mathrm{mL}$ in raw cow's milk and less than $10 \mathrm{CFU} / \mathrm{mL}$ in pasteurized milk. Moreover, there must not be any Escherichia coli per mL of pasteurized milk(6).

Endotoxin is a pyretic material in the cell walls of gramnegative bacteria and is usually called pyrogen. It has the structure of a lipopolysaccharide with a very toxic lipid, and it is of very low variety. However, the polysaccharide part of endotoxin has antigenic properties and is of very high variety $(7,8)$. Researchers explain that the handling and storage of raw milk alters the endotoxin concentrations, which may explain previous contradictory findings regarding the beneficial modulating effects on innate immunity toward allergy prevention in early childhood (8).

Considering the importance of milk hygiene, this research intended to determine the endotoxin levels in raw cow's milk and coliform contamination of them.

\section{Methods}

In this research, random samples of raw cow's milk $(n=43)$ were collected between April to September 2016. 
About $500 \mathrm{~mL}$ of unpasteurized milk were collected from the milk container, aseptically. The samples were immediately transported, in an icebox, to the laboratory. The $\mathrm{pH}$ values of milk samples were measured using a $\mathrm{pH}$ meter (9).

The total bacterial count was carried out according to the national standard No. 5484 using the pour plate method. Serial dilution $\left(10^{-1}\right.$ to $\left.10^{-8}\right)$ of the milk samples were made and $1 \mathrm{~mL}$ of each dilution was inoculated into duplicate plates of standard plate count agar and incubated at $30^{\circ} \mathrm{C}$ for 48 hours to determine the aerobic plate counts (10).

\subsection{Total Coliforms Count}

The MPN method was employed to identify coliform contamination of milk according to national standard No. 5234. The growth and appearance of colony on violet red bile agar, after 24 hours, at $35^{\circ} \mathrm{C}$, were considered for a presumptive count. The growth and gas production in $2 \%$ brilliant green broth were used as the confirmatory test for coliforms. The isolated coliform bacteria were identified to genus and species using differential biochemical tests including MR, VP, citrate utilization, endol production, $\mathrm{H}_{2} \mathrm{~S}$ production, motility, and fermentation in TSI agar $(11,12)$.

\subsection{Molecular Identification of Coliforms}

Cloning and sequencing of the beta-galactosidase gene (the LacZ gene) were performed by specific 326 bp long primers including the forward primer (5' ATGAAAGCTGGCTACAGGAAGGCC 3') and the reverse primer (5' GGTTTATGCAGCAACGAGACGTCA 3') (13). The PCR was carried out in a thermocycler (model Gradient Master, Eppendorf, Germany). For each PCR, $17 \mu \mathrm{L}$ of sterile distilled water, $2.5 \mu \mathrm{L}$ of $10 \mathrm{X}$ buffer, $1.5 \mu \mathrm{L}$ of $50 \mathrm{mM} \mathrm{MgCl}_{2}, 1 \mu \mathrm{L}$ of $10 \mathrm{mM}$ dNTPs, $1 \mu \mathrm{L}$ of each of the forward and reverse primers (10 pmol), $0.5 \mu \mathrm{L}$ of DNA template, and $0.5 \mu \mathrm{L}$ of Taq polymerase were used. The total volume of the reaction mixture was raised to $25 \mu \mathrm{L}$. The thermal regime in the thermocycler was adjusted as follows: initialization step at $94^{\circ} \mathrm{C}$ for 4 minutes followed by 35 cycles including the denaturation step at $94^{\circ} \mathrm{C}$ for 30 seconds, the primer-annealing step at $48^{\circ} \mathrm{C}$ for 35 seconds, and the amplification step of the desired segment at $72^{\circ} \mathrm{C}$ for 60 seconds. The final step at $72^{\circ} \mathrm{C}$ for 7 minutes ended the thermal cycle. Electrophoresis on $1 \%$ agarose gel was performed to ensure that the PCR conditions yielded the desired product. The samples were sent to the Sequetech company, USA, for sequencing using the Sanger method by employing an ABI 96 capillary instrument. The results of the sequencing were analyzed by using the Chromas software. Similarity of each sequence with the gene sequences in the NCBI database GenBank was determined using the BLAST software (14).

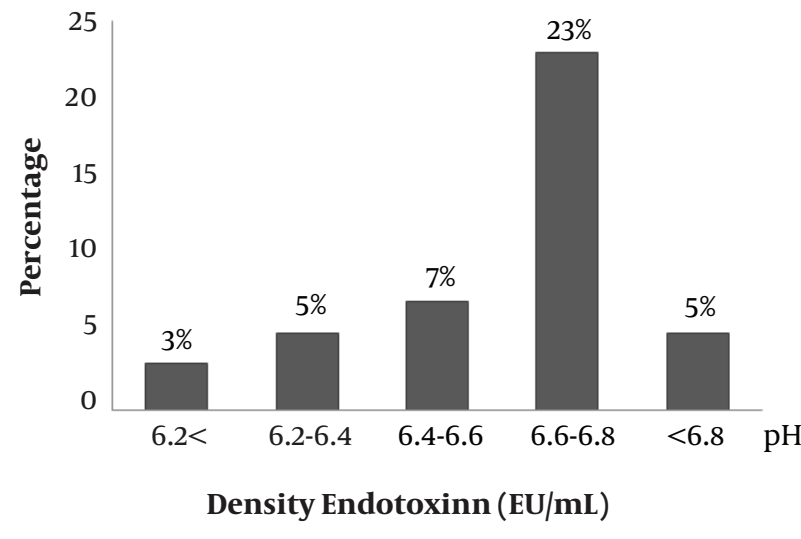

Figure 1. Distribution of $\mathrm{pH}$ of cow's milk samples

\subsection{Measuring Endotoxin Level}

Endotoxin levels were measured using limulus amebocyte lysate (LAL) kits manufactured by the American company Lonza. At first, $200 \mu \mathrm{L}$ of the milk inoculated to LAL vial, the content of the vial was completely mixed using a shaker, $100 \mu \mathrm{L}$ of the mixture in the vial was added to vial containing $100 \mu \mathrm{L}$ of the endotoxin-free water, the content of this vial was mixed, and $100 \mu \mathrm{L}$ of it was added to vial 2, which contained $100 \mu$ L of the endotoxin-free water. In this way, endotoxin concentrations of $0.250,0.125$, and 0.063 unit $/ \mathrm{mL}$ were prepared. All vials were placed in an incubator at $37^{\circ} \mathrm{C}$ for 1 hour and then examined for clot formation or gelation. The presence of milk clots indicated endotoxin contamination and lack of milk clots indicated the absence of endotoxin (15). The standard strain of Escherichia coli (ATCC: 25922) was used as positive control. Endotoxin-free water was used as negative control (16).

\subsection{Statistical Analysis}

Data were analyzed using the statistical package for social sciences (SPSS-Ver.17).

Significant differences between contaminated milk and endotoxin level $(\mathrm{P}<0.001)$ were determined by using Mann-Whitney test. Sample size was calculated based on valid statistical tests.

\section{Results}

This research studied 43 raw cow's milk samples. Figure 1 shows the $\mathrm{pH}$ of the milk samples.

Bacterial counts were converted to Log10/mL and were clustered as showed in Figure 2. The standard MPN was 
used to determine the probable number of coliform bacteria. Complementary tests on raw cow's milk samples indicated that $39.5 \%$ of them (17 samples) contained coliforms. Biochemical tests and molecular identification of the isolated coliforms revealed that 10 (23.25\%) of the milk samples contained E.coli, 5 (11.62\%) Enterobacter spp., 2 (4.65\%) K.pneumoniae, and about $60.5 \%$ of the samples were free of coliforms contamination.

Based on the results of endotoxin detection, it was found that the number of positive cases increased only at higher endotoxin concentrations when concentrations of amebocyte in the LAL test were raised so that 17 milk samples contained 0.250 endotoxin unit $/ \mathrm{mL}, 6$ milk samples contained $0.125 \mathrm{unit} / \mathrm{mL}$, and 20 milk samples contained $0.063 \mathrm{unit} / \mathrm{mL}$. Figure 4 shows endotoxin levels in the 43 raw cow's milk samples together with endotoxin levels in contaminated and uncontaminated milk samples.

Based on the diagram, none of the contaminated milk samples contained endotoxin at $0.063 \mathrm{unit} / \mathrm{mL}$. In other words, 94.1\% (16 contaminated samples) contained endotoxin at $0.250 \mathrm{unit} / \mathrm{mL}$ and only in 1 sample (5.9\%) the measured endotoxin level was $0.125 \mathrm{unit} / \mathrm{mL}$. Moreover, as expected, $76.8 \%$ (20 of the 26 uncontaminated samples) contained endotoxin at $0.063 \mathrm{unit} / \mathrm{mL}, 19.2 \%$ ( 5 of the 26 uncontaminated samples) contained endotoxin at 0.125 unit/mL, and only 1 of the 26 uncontaminated samples (3.9\%) contained endotoxin at $0.250 \mathrm{unit} / \mathrm{mL}$.

Statistical analysis showed that there was a significant relationship between the coliform contamination in raw cow's milk samples and the presence of endotoxin at 0.250 unit/mL $(\mathrm{P}<0.001)$, however, there was no significant relationship between coliform contamination of raw cow's milk samples and endotoxin concentrations of 0.125 and $0.063 \mathrm{unit} / \mathrm{mL}$. In other words, we can conclude that unpasteurized milk samples were contaminated with coliforms that contained endotoxin at higher concentrations than $0.063 \mathrm{unit} / \mathrm{mL}$.

Furthermore, the statistical analysis indicated that there was a significant relationship between lack of contamination with coliforms in raw cow's milk samples and endotoxin concentration at $0.063 \mathrm{unit} / \mathrm{mL}$ in the samples $(\mathrm{P}<0.001)$, however, there were no significant correlations between lack of coliform contamination in raw cow's milk samples and endotoxin concentrations of 0.125 and 0.250 unit/mL. In other words, we can conclude that raw cow's milk samples that were not contaminated with coliforms contained endotoxin at concentrations lower than 0.125 unit/mL.

\section{Discussion}

Milk is nutritious and highly nutritious nature of milk makes it a suitable medium for growth and proliferation of microbes. This research intended to compare endotoxin levels and coliform contamination of raw cow's milk. Most of all cow's milk samples have a nearly neutral $\mathrm{pH}(28 \%)$. We found that $39.5 \%$ of the samples contained coliforms and $60.5 \%$ of the samples were free of coliforms. The coliform bacteria isolated from the 17 contaminated samples were identified by PCR. Results showed that samples were contaminated with Escherichia coli, Enterobacter, and Klebsiella.

Considering the results of this research, the high microbial load in raw milk and traditional dairy products in Iran is confirmed, which could probably be due to unsanitary milking equipment and milk collection containers, unhygienic milking practices by workers and disregard for hygiene practices by milk sellers. Moreover, since bacteria die at high temperatures and the collected samples were not boiled at $100^{\circ} \mathrm{C}$, the high microbial load and the presence of coliforms in milk samples were expected. Furthermore, since the samples were collected in the summer, the chances of milk contamination during transportation from the dairy farms to the milk stores rose.

In the study on 220 samples of milk and other dairy products sold at food stores conducted by BehzadianNezhad in Qom (1999), the maximum and minimum contamination levels were those of milk and ice cream, respectively. They found that $10.1 \%$ of the samples were contaminated with coliforms, however, Escherichia coli contamination were not detected. In the present research, E.coli were isolated from $23.25 \%$ of milk samples.

Zolfaghari et al., studied 903 samples of milk and different dairy products with respect to bacteriological quality. Results indicated that 809 (89.6\%) of the samples had acceptable quality however, 94 (10.4\%) of the samples were of unacceptable quality. Mesophyll aerobic bacterial levels were acceptable in 238 (96.9\%) of the samples, Escherichia coli in 228 (92.7\%) of the samples, and coliforms in 222 (90.2\%) of the samples. In all, contaminating microorganisms were detected in the samples at levels that exceeded the permissible ones (17). However, in the present study, 26 (60.5\%) of the 43 raw milk samples in the Isfahan province had permissible levels of bacterial contamination (and the milk samples were of acceptable quality); bacterial contamination exceeded the permissible levels and the milk samples were of unacceptable quality in 17 (39.5\%) of the samples.

Fadaei et al. (18), compared levels of bacteriological contamination in 300 raw milk and 120 pasteurized milk samples in Shahr-e Kord. They found that 208 (70\%) of the raw milk samples were contaminated with E.coli and 242 


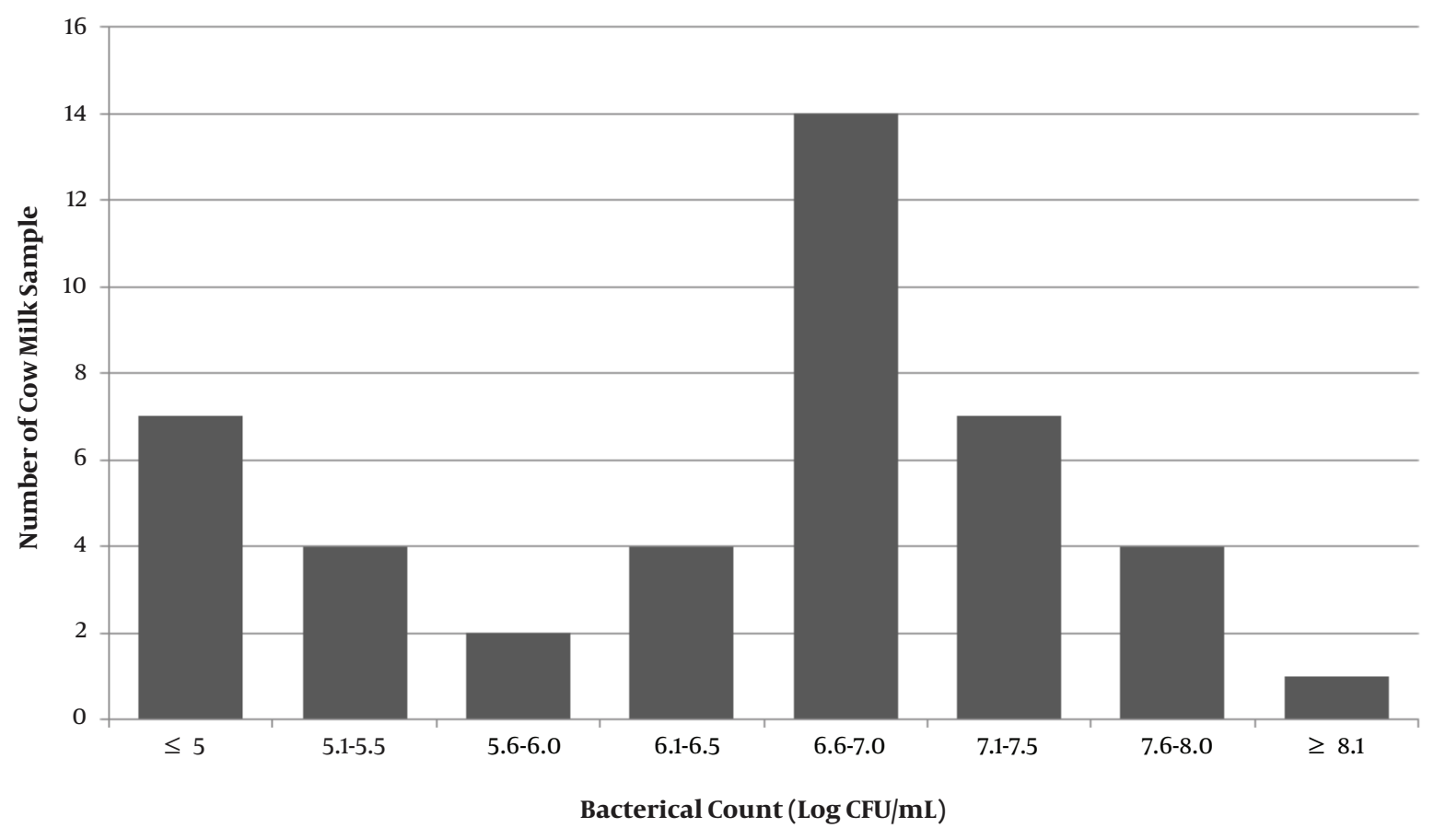

Figure 2. Bacterial count of raw cow's milk sample

\section{$\begin{array}{lllllllllll}16 & 18 & 19 & 21 & 24 & 36 & 41 & 43 & \text { C } & \text { M }\end{array}$}

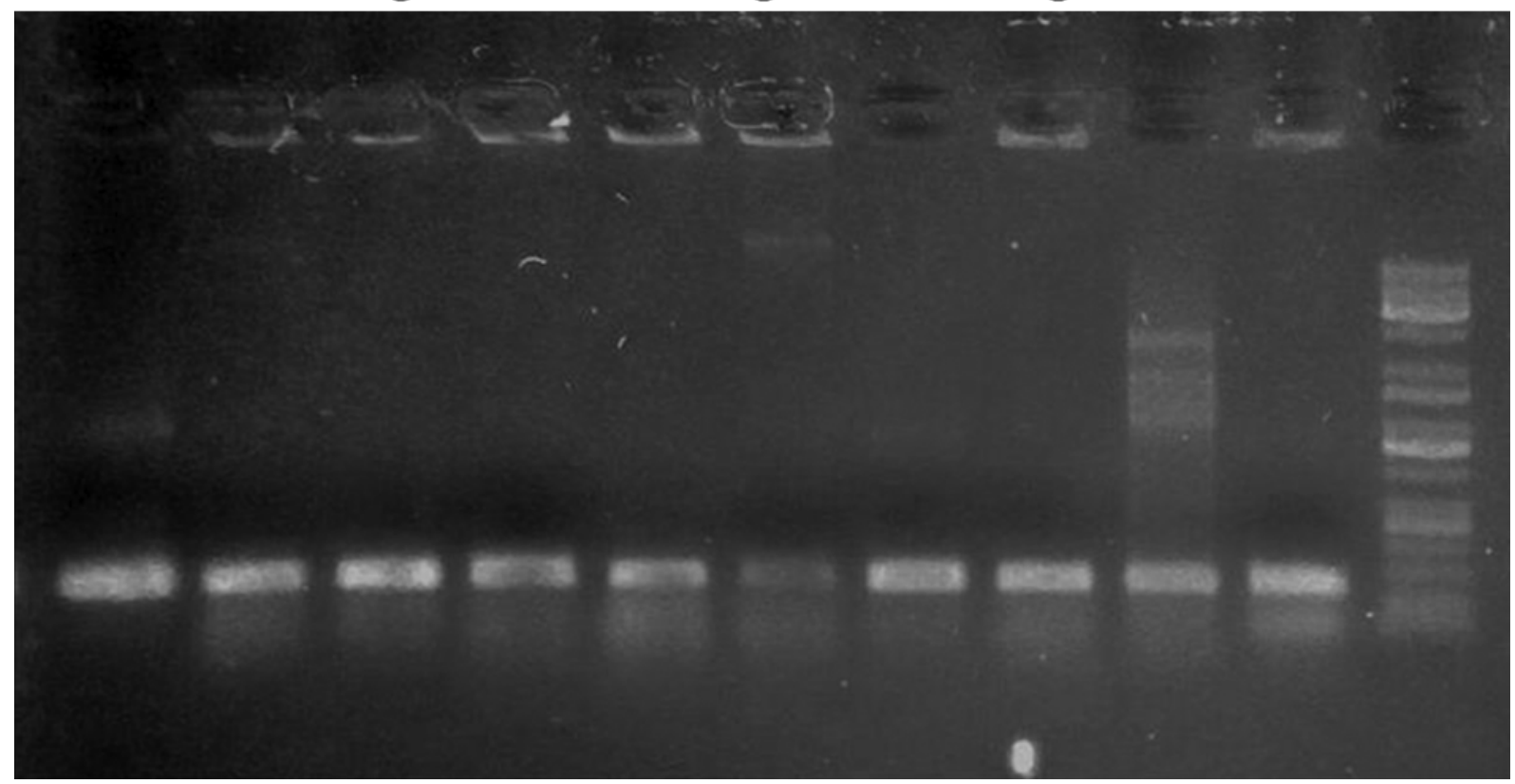

Figure 3. Agarose gel analysis of PCR amplification product using lacZ sequence, C: E.coli (ATCC 25922), Line1 - 9 indicates 326 bp size amplicon of samples (43, 41, 36, 27, 24, 21, $19,18,16$, respectively); M: marker 


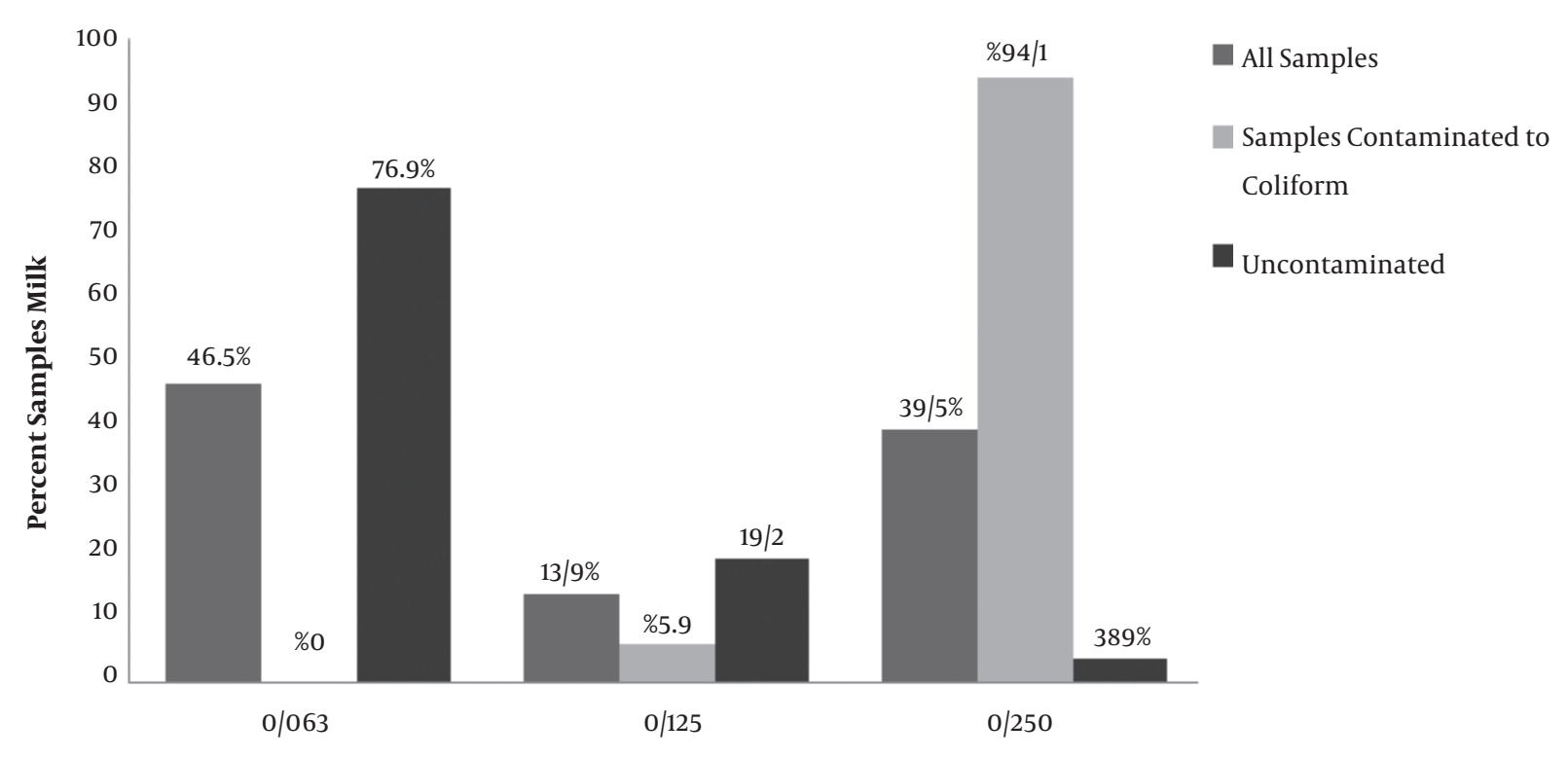

Density Endotoxin (EU/mL)

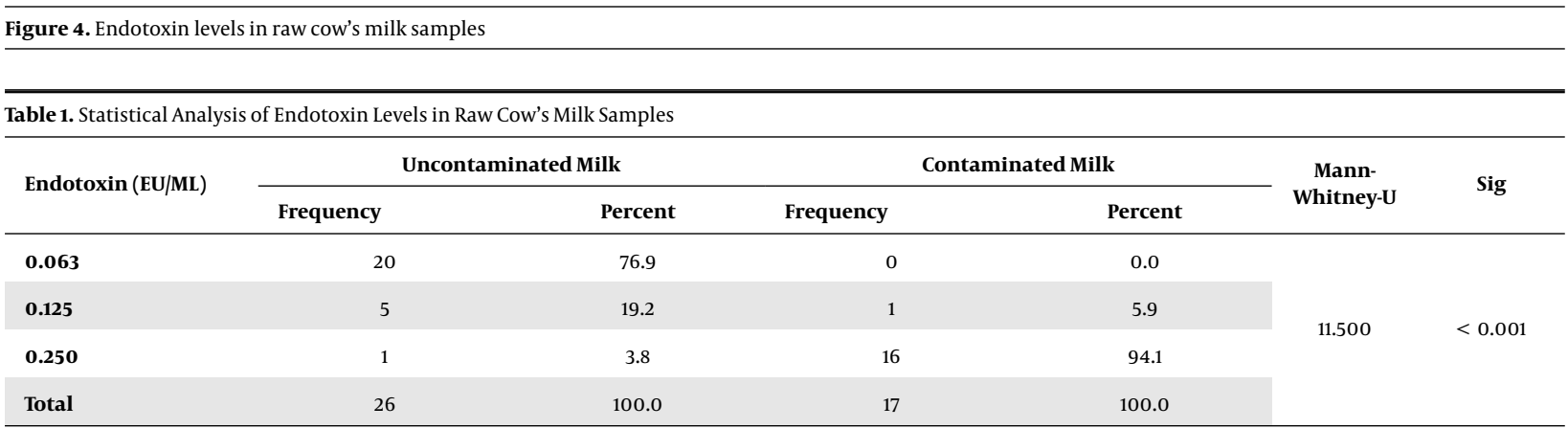

of the samples with coliforms (80.5\%). The maximum level of contamination with coliforms and E.coli was reported in the summer. However, in the present study, 10 (23.25\%) of the raw milk samples were contaminated with E.coli and 17 of the raw milk samples (39.5\%) were contaminated with coliforms. These results conform to those found by Fadaei et al. (18), with respect to high levels of coliform and E.coli contamination levels in the raw milk samples.

Hansen et al. (19), used the LAL test in Denmark to study gram-negative bacteria and lipopolysaccharide levels in milk samples and concluded that the heat resistant lipopolysaccharide level in all milk samples was less than 1 endotoxin unit/mL. They reported a significant positive relationship between the number of Gram-negative bacteria and lipopolysaccharide level in the samples. The present research also observed a significant relationship between the presence of coliform bacteria (that are gram-negative bacteria and contain lipopolysaccharide) and endotoxin levels in the raw milk samples.

Employing the LAL test, the researchers conducted a study to assess endotoxin levels in raw cow's milk at dairy farms and stores selling milk in several European countries. It was concluded that endotoxin levels varied in different European countries (20). The endotoxin levels in the stores were much higher compared to the dairy farms, which could be attributed to milk transportation from the dairy farms to the stores and to its storage in the stores (21). These results agree with those of the present research with respect to the high levels of endotoxin contamination in raw milk samples. Considering the fact that the samples in the present research were taken only from the stores in the city and all of the samples contained endotoxin, we can attribute milk contamination to a large extent to the sanitary conditions in the stores and to the hygienic status of 
milk retailers.

In the study that Spika conducted on milk samples taken from dairy farms and milk stores by using the LAL test, endotoxin levels were assessed and it was found that their levels in the samples taken from the stores were higher compared to those taken from the dairy farms (8). This suggested that increases and decreases in milk temperature changed endotoxin levels in milk. In the present research, in which milk temperature was not considered, a high percentage of raw milk samples taken from the stores in Isfahan tested positive for endotoxin.

Suzuki et al. (15), employed the LAL test to study endotoxin levels in raw milk samples taken from completely healthy cows and from cows suffering from mastitis caused by gram-positive and coliforms bacteria. He observed that endotoxin levels in cows with mastitis resulting from gram-positive bacterial infection varied from 0.28 to 450 units/mL while the average endotoxin level in milk taken from cows with mastitis was 11523.5 units/mL. He concluded that endotoxin levels in milk taken from cows with mastitis were directly related to coliform mastitis. In the present study, in which the health of the cows was not considered, all of the samples tested positive for endotoxin, and 17 samples contained 0.250 , six samples 0.125 , and 20 samples 0.063 units of endotoxin/mL. Therefore, it is consistent that the handling and storage of raw milk alters the coliform contamination, which may explain findings regarding the endotoxin concentrations. There was also a significant relationship between coliforms contamination in raw milk and the presence of 0.250 units of endotoxin per milliliter of the raw cow's milk samples.

There were some unavoidable limitations in our study. First, due to the inaccessibility and the high cost of the LAL kit, this research was done on a small size of cow's milk samples. Second, this research was conducted in the summer. Performing research in different seasons can provide comparable results.

\section{Acknowledgments}

This work was a part of MSc thesis of F. Afshari Asfidoajani at the Islamic Azad University, Isfahan, Iran (No: 17230507931029). The Authors would like to thank the research laboratory personnel for their cooperation in this investigation.

\section{Footnotes}

Authors' Contribution: Two authors had an equal role in design, work, statistical analysis, and manuscript writing.

Conflict of Interests: The authors declare no conflict of interest.
Funding/Support: Islamic Azad University.

\section{References}

1. Haug A, Hostmark AT, Harstad OM. Bovine milk in human nutritiona review. Lipids Health Dis. 2007;6:25. doi: 10.1186/1476-511X-6-25. [PubMed: 17894873]. [PubMed Central: PMC2039733].

2. Thorning TK, Raben A, Tholstrup T, Soedamah-Muthu SS, Givens I, Astrup A. Milk and dairy products: good or bad for human health? An assessment of the totality of scientific evidence. Food Nutr Res. 2016;60:32527. doi: 10.3402/fnr.v60.32527. [PubMed: 27882862]. [PubMed Central: PMC5122229].

3. Ansari T, Hesari J, Ahmadi A, Giasifar S, Aiaseh A. Effects of CO2 Addition to Raw Milk on Microbial, Physiochemical and Sensory Properties of Probiotic Set Yoghurt. JAgric Sci Technol. 2013;15(2):253-63.

4. Stessl B, Hein I. Identifying pathogens in milk. In: Griffiths MW, editor. Improving the Safety and Quality of Milk. Woodhead; 2010. p. 87-112. doi: 10.1533/9781845699420.2.87.

5. Mahon CR, Lehman DC, Manuselis G. Textbook of Diagnostic Microbiology. 5th ed. Philadelphia: Saundera Elsevier; 2015.

6. Ledenbach LH, Marshall RT. Microbiological Spoilage of Dairy Products. In: Doyle MP, Sperber WH, editors. Compendium of the Microbiological Spoilage of Foods and Beverages. New York: Springer Science \& Business Media; 2009. p. 41-67. doi:10.1007/978-1-4419-0826-1_2.

7. Ametaj BN, Zebeli Q, Iqbal S. Nutrition, microbiota, and endotoxinrelated diseases in dairy cows. Brazil J An Sci. 2010;39(suppl spe):43344. doi: 10.1590/s1516-35982010001300048.

8. Sipka S, Beres A, Bertok L, Varga T, Bruckner G. Comparison of endotoxin levels in cow's milk samples derived from farms and shops. Innate Immun. 2015;21(5):531-6. doi: 10.1177/1753425914557100. [PubMed: 25527628].

9. Tsioulpas A, Lewis MJ, Grandison AS. A study of the $\mathrm{pH}$ of individual milk samples. Int J Dairy Technol. 2007;60(2):96-7. doi:10.1111/j.14710307.2007.00308.x.

10. International Organization for Standardization. ISO 4833: Microbiology of food and animal feeding stuffs - Horizontal method for the enumeration of microorganisms - Colony-count technique at 30 degrees C. ISO; 2003. Available from: https://www.iso.org/standard/34524.html.

11. Anderson M, Hinds P, Hurditt S, Miller P, McGrowder D, AlexanderLindo R. The microbial content of unexpired pasteurized milk from selected supermarkets in a developing country. Asian Pac J Trop Biomed. 2011;1(3):205-11. doi: 10.1016/s2221-1691(11)60028-2.

12. Bali OS, Lajnef R, Felfoul I, Attia H, Ayadi MA. Detection of Escherichia coli in unpasteurized raw milk. Int J Agric Food Sci. 2013;3(2).

13. Maheux AF, Boudreau DK, Bisson MA, Dion-Dupont V, Bouchard S, Nkuranga $\mathrm{M}$, et al. Molecular method for detection of total coliforms in drinking water samples. Appl Environ Microbiol. 2014;80(14):407484. doi: 10.1128/AEM.00546-14. [PubMed: 24771030]. [PubMed Central: PMC4068683].

14. Kampfer P, Nienhuser A, Packroff G, Wernicke F, Mehling A, Nixdorf $\mathrm{K}$, et al. Molecular identification of coliform bacteria isolated from drinking water reservoirs with traditional methods and the Colilert-18 system. Int J Hyg Environ Health. 2008;211(3-4):374-84. doi: 10.1016/j.ijheh.2007.07.021. [PubMed: 17870668].

15. Suzuki Y, Suzuki K, Shimamori T, Tsuchiya M, Niehaus A, Lakritz J. Evaluation of a portable test system for assessing endotoxin activity in raw milk. J Vet Med Sci. 2016;78(1):49-53. doi: 10.1292/jvms.15-0370. [PubMed: 26279135]. [PubMed Central: PMC4751116].

16. Mottar J, De Block J, Merchiers M, Vantomme K, Moermans R. Routine limulus amoebocyte lysate (LAL) test for endotoxin determination in milk using a Toxinometer ET-201. J Dairy Res. 1993;60(2):223-8. [PubMed: 8320369]. 
17. Zolfaghari MR, Gaeini R, Kalhor N, Khalilian M, Razavian $M H$ Soleimani Sasani M. [Study of microbial contamination of milk and pasteurization dairy products in Qom province]. J Microbial World. 2012;5(1-2):47-57. Persian.

18. Fadaei A, Jamshidi E, Kheiri S. [Comparison of bacterial contamination of raw and pasteurized milk used in Shahrekord in 2006]. J Shahrekord Univ Med Sci. 2008;10. Persian.

19. Hansen K, Mikkelsen T, Moller-Madsen A. Use of the Limulus test to determine the hygienic status of milk products as characterized by levels of gram-negative bacterial lipopolysaccharide present. J Dairy Res. 1982;49(2):323-8. [PubMed: 7096722].
20. Garbaj AM, Awad EM, Azwai SM, Abolghait SK, Naas HT, Moawad AA, et al. Enterohemorrhagic Escherichia coli 0157 in milk and dairy products from Libya: Isolation and molecular identification by partial sequencing of 16S rDNA. Vet World. 2016;9(11):1184-9. doi: 10.14202/vetworld.2016.1184-1189. [PubMed: 27956766]. [PubMed Central: PMC5146295].

21. Gehring U, Spithoven J, Schmid S, Bitter S, Braun-Fahrlander C, Dalphin JC, et al. Endotoxin levels in cow's milk samples from farming and non-farming families - the PASTURE study. Environ Int. 2008;34(8):1132-6. doi: 10.1016/j.envint.2008.04.003. [PubMed: $18502510]$ 